\title{
Measures for the Study of Maternal Teaching Strategies
}

\author{
Luis M. Laosa \\ Educational Testing Service
}

A technique to measure maternal teaching strategies was developed for possible use in research and evaluation studies. Scores derived from the technique describe both quality and quantity of behaviors used by mothers to teach cognitive-perceptual tasks to their own young children. The maternal teaching observation technique (MTOT) yields scores on the following teaching strategy dimensions: inquiry, directive, praise, negative verbal feedback or disapproval, modeling, visual cue, physical affection, positive physical control, and negative physical control. English and Spanish versions of the technique were developed. The technique was administered to 83 different mother-child dyads of two sociocultural and language groups, Anglo-American and Chicano. The tasks and procedures were sufficiently engaging and appealing, in terms of difficulty level and ability to elicit and to maintain the subjects' attention, for mothers and their 5-year-old children in both groups. Interobserver reliabilities and parallel-form consistency were adequate for both groups, indicating that each MTOT scale measures a moderately stable attribute of maternal behavior. Group differences in intercorrelations suggest that construct invariance might not exist across sociocultural or language groups.

The importance of understanding teaching and learning within the family is a focus of growing concern. In addition to the contem-

APPLIED PSYCHOLOGICAL MEASUREMENT

Vol. 4, No. 3 Summer 1980 pp. 355-366

(C) Copyright 1980 West Publishing Co. porary issues that underlie this concern, the family is always a setting in which important educational encounters take place.

Research on teaching and learning in families is handicapped by difficulties involved in obtaining adequate measures. Data obtained through self-report and retrospective reports sometimes present problems of validity. Direct observation procedures are not without methodological problems, and their use requires considerable training, time, and expense. However, the direct observation approach, if conceptualized and implemented appropriately, requires fewer assumptions and inferences than procedures based solely on report and, at least potentially, it represents a significant methodological improvement.

The purpose of this investigation was to develop a technique that may, at least provisionally, serve as a set of measures in subsequent investigations of teaching in families. Such a technique should be sufficiently complex to represent at least some of the significant aspects of teaching situations confronted in reality, yet sufficiently simple to allow for the control and standardization required of well-designed psychometric procedures. An attempt to measure teaching strategies of mothers with their young children began the investigation, with the idea that, if successful, the methods might later be adapted to include other aspects of the interac- 
tion in teaching and learning, as well as other age groups. The scope of the present work was (1) to construct a technique to measure several dimensions of maternal teaching behavior; (2) to assess the acceptability of the measures from the standpoint of certain psychometric properties; and (3) to determine the adequacy of the measures for use with subjects from two different cultural-linguistic populations.

\section{Assumptions}

Although the maternal teaching observation technique was constructed to a large extent on an empirical basis, certain assumptions underlie its development, the selection of behavior categories it assesses, and the approach to assessing them. The primary assumption is that maternal teaching behavior is manifold and is composed of various types of observable behaviors. Parents and children influence each other in many ways, and maternal teaching behaviors vary on many dimensions. When a mother interacts with her child, she may influence the child in many different ways to bring about the kind of behavior she wishes. She can attempt to initiate certain kinds of behavior in the child and to suppress or to ignore others. The categories of maternal behavior included in the observation technique were selected on the basis of these influencing characteristics of the mother.

Another assumption is that maternal teaching behavior functions like a dispositional variable, so that unless unusual acceleratory or inhibitory forces are present, members of a population would be expected to remain fairly stable in their performance relative to one another. Because of this stability in relative positions, consistent individual and group differences would be expected. Such stability may not appear in absolute level of performance, however, which may fluctuate as a function of the type of situation or the nature of the task being taught (Brophy, 1970).

A third assumption is that the mother's behavior in the observed structured situation is representative of her teaching behavior during everyday situations in which she might attempt to teach the child similar tasks. Evidence for this type of validity comes from a recent large-scale study (Stallings \& Porter, in prep.). These investigators observed the behavior of caregivers in the home during two situations: (1) a structured situation in which caregivers were asked to teach the children a Play-Doh Factory task and (2) a naturalistic situation in which caregivers and children were free to interact as they normally would if the observer were not present. The same observation instrument was used to record caregiver behaviors during the two types of situations. Correlations computed to examine the relationships between the two types of observations were, in general, of moderate magnitude. These results provide evidence for the validity of techniques such as that described in this paper.

A fourth assumption is that it is possible to construct overt behavior categories that will have fairly wide applicability for assessing maternal teaching behavior. A review of the literature, together with the experience of observing mothers teach their own young children, provided the basis for ascertaining what categories of maternal behavior would be considered for inclusion in the technique. The psychology of teaching has been approached from a variety of points of view, although those conducting research on it have focused primarily on classroom instruction, devoting relatively little attention to the question of how parents teach their own young children. Different aspects of the instructional process have been emphasized, depending on the investigators' point of view. Thus, the recent literature on cognitive development has underscored the importance of an inquiry-based approach to teaching (Flavell, 1977; Sigel \& Saunders, 1979). On the other hand, the results of research on observational learning and imitation suggest that modeling plays a central role in instruction (Bandura, 1977). Others see positive and negative reinforcement as principal concepts in instruction; reinforcement is seen to 
have both motivational and informational functions. Still others place the emphasis on attentional processes: teaching behaviors aimed at influencing attention and selective perception are seen to play an essential instructional role, as they serve to modify the flow of information from the sensory register to the short-term memory for storage or further processing (Berliner \& Gage, 1976; Gagné, 1976). An attempt was made to include among the categories of behavior assessed by the maternal teaching observation technique a sample of the instructional processes emphasized by diverse views of the psychology of teaching.

Practical considerations also guided the selection of categories. The number of categories included in the technique was chosen so that the observation procedure could yield data on a set of behaviors that would be amenable to manual recording and reliable coding by a trained human observer during the conduct of an on-going mother-child interaction around the type of tasks employed. A related criterion apṕlied to the selection of categories was the ease of identification. This criterion can be applied only when the categories can be precisely and clearly defined (Moustakas, Sigel, \& Schalock, 1956). That is, trained observers must find the relevant behaviors relatively easy to identify and to label. For this reason certain details of behavior were omitted from the technique. The greater the ease with which observers could label the observed behavior, the greater the chance for observer agreement.

The criterion that guided the selection of tasks and their difficulty levels was that a broad range of teaching behaviors would be elicited from mothers with their 4- to 7-year-old children by materials and activities of approximately equal degree of familiarity for the sociocultural populations represented in the study.

\section{The Maternal Teaching Observation Technique}

Two parallel forms of the technique were developed. The technique may be administered in the subject's home or in the laboratory. After establishing rapport, the mother is asked to sit at a table next to her child. The mother is given an assembled Tinkertoy model and all the disassembled parts necessary for making an identical model. (The parts of the assembled model are glued together to prevent their being taken apart, and the disassembled parts are "worked" in and out prior to using them with the subjects until none is unusually difficult for a child to fit into any other part.) The mother is asked "to teach" her child "how to make" a model like the one already assembled and to do this as she would if the observer were not present. If others are present, they are asked not to participate and to be very quiet. The observer manually records on a protocol the frequency of occurrence of the following maternal behavior categories:

Inquiry. The mother asks the child a question or otherwise directs a verbal inquiry to the child. Directive. The mother verbally commands the child to pursue a given course of action.

Praise. The mother praises, or otherwise verbally expresses approval of, the child or the child's activity or product.

Negative verbal feedback or disapproval. The mother verbally indicates to the child that a given course of action taken by the child is incorrect or that she is displeased with the child or the child's activity or product.

Modeling. The mother works on the model and the child observes. A behavior unit is considered complete (and a frequency point is recorded) every time the mother fastens or unfastens two parts.

Visual cue. The mother attempts to attract the child's attention toward a given aspect of the task by providing a visual cue. This category is limited to attempts to attract the child's attention by sliding, pushing, or lifting a part or portion of the model being assembled (but short of fastening or unfastening any parts). The behavior unit is considered complete (and a frequency point is recorded) when the mother releases the part or portion of the model or otherwise moves her hand away 
from it. (More subtle visual cues, such as pointing and touching a part, were included as additional categories but were deleted from subsequent analyses because their interobserver reliabilities and parallel-form consistency were, in general, only moderate in magnitude.) ${ }^{1}$

Physical affection. The mother makes physical contact with the child as an expression of a favorable feeling toward the child.

Positive physical control. The mother manually controls the child's motor behavior to facilitate the child's solution of the task, e.g., turning the child's body toward the task or restraining the child as the child tries to leave the task area.

Negative physical control. This category includes two classes of nonverbal behavior, both displaying the mother's disapproval of the child's activity on the task or product: (1) an action that generally would be interpreted as physical punishment (e.g., slapping the child's hand); or (2) manually restraining or controlling the child's motor activity as the child works on the task in order to keep him or her from pursuing what the mother apparently perceives as action not conducive to learning or solving the task, or not appropriate for that particular time (e.g., she takes or pushes the child's hand away from the task material or she holds the child's arm as the child begins to reach for a Tinkertoy part).

For each parallel form, the observation is discontinued 5 minutes after the mother is signalled to begin teaching or when the task is com-

${ }^{1}$ For pointing, the interobserver reliabilities during data collection (Spearman rank-order correlations, $n=10$ ) were .45 , $p<.10$, one-tail test, for Parallel Form A and .73, $p<.009$, for Form B. For touching a part, the reliability coefficients were $.79, p<.003$, for Form A, and .54, $p<.05$, for Form B. The parallel-form consistency (Spearman rank correlation) for pointing was $.41, p<.005$, one-tail test, for the AngloAmerican sample $(n=40)$, and $.39, p<.005$, for the Chicano sample $(n=43)$. For touching a part, the parallel-form consistency was $.58, p<.001$, for Anglo-Americans and $.59, p<$ .001 , for Chicanos. pleted, whichever occurs first. The observation time in seconds is recorded. The coordinated use of a timer and a stop watch can allow the observer to monitor time in a manner that should be free of distraction to both observer and subjects.

The two parallel forms of the technique differ from one another only in the Tinkertoy models employed. Both models appear on page 5 of the Tinkertoy Instruction and Idea Book (Questor Education Products Company, 1972). Form A employs the "Robot," and Form B the "Jet Airplane." They consist of 27 and 28 parts, respectively. Both are of approximately equal difficulty.

\section{Scores}

Several types of scores can be derived from the data yielded by the maternal teaching observation technique. Each category is initially scored for its frequency of occurrence. Individual categories may be combined to obtain broader superordinate categories. To adjust for individual subject variability in session length (observation time), rate scores can be computed dividing each raw frequency by observation time. These rate scores can be summed across the two parallel forms to yield summed-rate scores. Rate-per-minute scores can be computed by dividing each raw frequency by the observation time (in seconds) and multiplying the quotient by 60 . These rate-per-minute scores can be summed across the two parallel forms and each sum can be divided by 2 to yield average rateper-minute scores. Other scores can be derived. The choice of scores should be guided by the research questions and statistical analysis plan of each study (see, e.g., Laosa, 1978, 1980, in pressb; Sackett, 1978).

\section{Data Collection}

\section{Spanish Administration}

As part of pilot testing the procedures, Chicano mothers who were equally fluent in 
both English and Spanish were administered the technique in both languages, using a counterbalanced-order design. It was found that using "Hoy quiero que Usted le enseñe a (niño) como hacer. ..." in the Spanish version of the instructions tended to elicit somewhat different maternal teaching strategies from the English version. Chicano mothers interpreted enseñar to mean to show. This Spanish version elicited modeling as a teaching strategy more frequently than did the English instructions to teach. "Hoy quiero que Usted haga que (niño) aprenda como hacer. ..." and

"Today I would like you to teach (child) how to make. ..." did not differ in the teaching strategies they elicited and therefore were used in the Spanish and English versions of the instructions, respectively.

\section{Description of the Samples}

Subjects were 83 Anglo-American and Chicano mother-child dyads. ${ }^{2}$ Each child was in kindergarten in one of three public schools in Los Angeles, California. From a pool of volunteers from the three schools, the samples were selected to be as representative as possible of Anglo-American and Chicano families with regard to formal educational level and occupational status. They were informed that the study was designed to increase knowledge about the conditions surrounding children's learning.

The Anglo-American sample. The AngloAmerican sample consisted of 40 mother-child dyads (19 boys, 21 girls). The mean age of the

\footnotetext{
${ }^{2}$ The term Chicano, or Mexican-American, as used in this study, refers to persons who were born in Mexico and now hold United States citizenship or otherwise live in the United States or whose parents or more remote ancestors immigrated to the United States from Mexico. It also refers to persons who trace their lineage to Hispanic or Indo-Hispanic forebears who resided within Spanish or Mexican territory that is now part of the southwestern United States. The term Anglo-American, as employed here, refers to all white, English-speaking persons who were born in the United States and are not Chicano or members of other Spanish-origin groups.
}

children was 70.1 months, $S D=4.5$, and of the mothers 30.6 years, $S D=4.6$. The number of years of formal education completed by the mothers ranged from an eleventh-grade education to eight years of post high school $(M=13.2$, $S D=2.0$ ). Forty-two percent of the mothers and all but four of the fathers were employed outside the home. The mothers' occupational status ranged from housewives not employed outside the home to service workers in other than private households to professional and technical workers. The fathers' occupational status ranged also from service workers in other than private households to professional and technical workers. All but three of the families were intact.

The Chicano sample. The Chicano sample consisted of 43 Chicano mother-child dyads (20 boys, 23 girls). The mean age of the children was 69.8 months, $S D=4.4$, and of the mothers 33.8 years, $S D=6.5$. The number of years of formal education completed by the mothers ranged from only a first-grade education to two years of college $(M=8.8, S D=3.4)$. Thirty-three percent of the mothers and all but three of the fathers were employed outside the home. The mothers' occupational status ranged from housewives not employed outside the home to service workers in other than private households to professional and technical workers. The fathers' occupational status ranged also from service workers in other than private households to professional and technical workers. All but one of the families were intact.

\section{Training the Observers}

A written description of the procedures and the operational definitions of the behavior categories, with examples, were given to the observer trainees and were explained in detail by the author over several sessions. The trainees practiced initially by simultaneously observing other assistants who role-played the maternal teaching behaviors. This was done until $100 \%$ agreement to within one frequency point was attained on 
every behavior category. Next, the trainees conducted observations in the homes of motherchild dyads similar to the ones employed as subjects. Their training was considered complete when they had achieved in these situations exact agreement to within one frequency point on every behavior category. The observers were two Chicano English-Spanish bilingual female university students.

\section{Procedures}

In collecting the data presented here, all procedures were conducted in the subjects' homes using the subjects' home language. Subjects were randomly assigned to observers. Each subject (mother-child dyad) was administered Parallel Forms A and B of the maternal teaching observation technique. Form A preceded Form $B$ in order of administration; the interval between administrations of the two forms was approximately 10 minutes.

\section{Results}

\section{Reliability}

In addition to interobserver reliability checks during the training of the observers, two types of reliability estimates were obtained: interobserver reliability during data collection and consistency across parallel forms.

To determine interobserver reliability, the two observers simultaneously but independently conducted observations on 10 different motherchild dyads selected at random intervals during the data collection phase of the project. Spearman rank-order correlations, corrected for ties, were computed between the raw frequencies obtained by the two observers on each of the 10 mother-child dyads. These estimates of interobserver reliability are shown in Table 1 . As can be seen, all of the coefficients were highly significant; they ranged in magnitude from .68 to .97 , median $=.86$, for Form A, and from .76 to .99 , median $=.95$, for Form B. Rho coefficients were

Table 1

Interobserver Reliability and Parallel-form Consistency for the Maternal Teaching Observation Technique (MTOT)

\begin{tabular}{|c|c|c|c|c|}
\hline \multirow[b]{2}{*}{ MTOT variables } & \multicolumn{2}{|c|}{$\begin{array}{c}\text { Interobserver } \\
\text { reliability }\end{array}$} & \multicolumn{2}{|c|}{$\begin{array}{l}\text { Paralle1-form } \\
\text { consistency }\end{array}$} \\
\hline & $\begin{array}{l}\text { Form A } \\
(\underline{\mathrm{n}}=10)\end{array}$ & $\begin{array}{l}\text { Form B } \\
(\underline{\mathrm{n}}=10)\end{array}$ & $\begin{array}{l}\text { Anglo- } \\
\text { Americans } \\
(\underline{n}=40)\end{array}$ & $\begin{array}{l}\text { Chicanos } \\
(\underline{\mathrm{n}}=43)\end{array}$ \\
\hline Inquiry & .83 & .90 & .69 & .75 \\
\hline Directive & .94 & .96 & .60 & .63 \\
\hline Praise & .72 & .99 & .68 & .69 \\
\hline Negative verbal feedback & & & & \\
\hline or disapproval & .90 & .95 & .42 & .47 \\
\hline Modeling & .97 & .98 & .72 & .83 \\
\hline Visual cue & .68 & .88 & .52 & .70 \\
\hline Physical affection & --- & --- & --- & --- \\
\hline Positive physical control & -- & -- & .68 & --- \\
\hline Negative physical control & -- & .76 & --- & -- \\
\hline
\end{tabular}

Note. Coefficients are Spearman rank correlations; all are significant beyond the .01 leve1, one-tail tests. Dashes indicate where coefficients were not computed because of zero or very low frequency; in these instances the interobserver reliability was 100 percent, and the parallel-form consistency was very high. 
not computed for the remaining variables because both observers obtained zero frequencies; the interobserver agreement for these variables was $100 \%$.

To determine the parallel-form consistency, Spearman rank-order correlations, corrected for ties, were computed between Form A and Form $B$ raw frequencies for each ethnic sample. These rho coefficients are shown in Table 1. As can be seen, these estimates of consistency are, in general, at least moderately high. They were all highly significant, ranging in magnitude from .42 to .72 , median $=.68$, for the Anglo-American sample and from .47 to .83 , median $=.70$, for the Chicano sample. Because of very low frequency, rho coefficients were not computed for the remaining variables; the parallel-form consistency was high also for these variables, as reflected in mean frequencies (zero and near-zero) that were highly similar across forms.

\section{Prior-Exposure Effect}

In 19 of the Anglo-American homes and 8 of the Chicano homes there was a Tinkertoy set prior to the administration of the maternal teaching observation technique. To determine whether such prior exposure to the task material had an effect on the observed maternal teaching behaviors, point-biserial correlations were computed between summed-rate scores on each of the variables and whether there was a Tinkertoy set in the home prior to the administration of the technique, separately for each ethnic sample. All but one of the coefficients were nonsignificant ( $p>.05$, two-tail tests). Physical affection ( $r$ $=.32$ ), in the Chicano sample, was the exception; however, because of the low frequency for this variable, not much confidence should be placed in this point-biserial coefficient. There was no evidence, then, of any effect as a result of prior exposure.

\section{Session Lengths}

As indicated earlier, for each parallel form the observation was discontinued 5 minutes after the mother was signalled to begin teaching or when the task was completed, whichever occurred first. Of the Anglo-American and Chicano samples, $32 \%$ and $30 \%$, respectively, completed the Form A task in less than 5 minutes. The Form A median session length (observation time in seconds) was 250 (minimum $=150$ ) for these 13 Anglo-American mother-child dyads and 218 (minimum $=160$ ) for these 13 Chicano dyads. Of the Anglo-American and Chicano samples, $18 \%$ and $26 \%$, respectively, completed the Form B task in less than 5 minutes. The Form B task median session length was 280 (minimum $=205$ ) for these 7 Anglo-American dyads and 235 (minimum $=176$ ) for these 11 Chicano dyads.

\section{Level of Performance}

The means, standard deviations, and standard errors for the rate-per-minute scores on each parallel form of the technique are shown separately for each ethnic group in Table 2 . As can be observed, the means and standard deviations are highly similar across parallel forms of the technique. Sign tests were computed separately for each ethnic group to test the hypothesis of no difference in the distribution of the variables between parallel forms. That none but one of the 18 sign tests was significant $(p>$ .10 , two-tail tests) indicates that in general the distributions of the variables did not differ across parallel forms of the technique. Modeling, for the Anglo-American sample, was the exception, $z=2.09, p<.05$.

The means and standard deviations of the average rate-per-minute scores are shown separately by dyad structure for each ethnic sample in Table 3. To compare scores obtained by mother-son and mother-daughter dyads, Mann-Whitney $U$ tests, corrected for ties, were computed separately by ethnic group. None of the $18 U$ tests was significant, and only one approached significance. Among Anglo-American subjects, mother-daughter dyads obtained higher modeling scores than mother-son dyads, $U=127.5, z=-1.95, p<.06$, two-tail test. 
Table 2

Means, Standard Deviations, and Standard Errors for Rate-per-minute Scores on Forms A and B of the Maternal Teaching Observation

Technique (MTOT): Anglo-American $(\underline{n}=40)$ and Chicano $(\underline{\mathrm{n}}=43)$ Samples

\begin{tabular}{|c|c|c|c|c|}
\hline \multirow[b]{2}{*}{ MTOT variables } & \multicolumn{2}{|c|}{ Anglo-Americans } & \multicolumn{2}{|c|}{ Chicanos } \\
\hline & Form A & Form B & Form A & Form $\mathrm{B}$ \\
\hline \multicolumn{5}{|l|}{ Inquiry } \\
\hline M & 2.22 & 2.12 & 1.55 & 1.34 \\
\hline$\overline{S D}$ & 1.14 & 1.22 & 2.07 & 1.50 \\
\hline$\underline{\mathrm{SE}}$ & .18 & .19 & .32 & .23 \\
\hline \multicolumn{5}{|l|}{ Directive } \\
\hline$\underline{\mathrm{M}}$ & 1.55 & 1.50 & 2.19 & 2.45 \\
\hline$\underline{\bar{S} \mathrm{D}}$ & 1.27 & 1.19 & 1.69 & 2.22 \\
\hline$\overline{\mathrm{SE}}$ & .20 & .19 & .26 & .34 \\
\hline \multicolumn{5}{|l|}{ Praise } \\
\hline$\underline{M}$ & 3.09 & 3.24 & 1.89 & 2.18 \\
\hline$\underline{S D}$ & 1.93 & 2.08 & 1.96 & 2.03 \\
\hline SE & .30 & .33 & .30 & .31 \\
\hline \multicolumn{5}{|c|}{$\begin{array}{l}\text { Negative verbal feedback } \\
\text { or disapproval }\end{array}$} \\
\hline$\underline{M}$ & .52 & .66 & .63 & 1.06 \\
\hline SD & .58 & .57 & .65 & 1.09 \\
\hline$\underline{\mathrm{SE}}$ & .09 & .09 & .10 & .17 \\
\hline \multicolumn{5}{|l|}{ Modeling } \\
\hline M & .84 & 1.09 & 3.17 & 3.03 \\
\hline$\underline{S D}$ & 1.38 & 1.30 & 2.90 & 3.26 \\
\hline$\underline{\mathrm{SE}}$ & .22 & .20 & .44 & .50 \\
\hline \multicolumn{5}{|l|}{ Visual cue } \\
\hline$\underline{\mathrm{M}}$ & 2.37 & 2.26 & 3.14 & 3.00 \\
\hline$\underline{S D}$ & 1.15 & 1.58 & 1.46 & 1.60 \\
\hline$\underline{\mathrm{SE}}$ & .18 & .25 & .22 & .24 \\
\hline \multicolumn{5}{|c|}{ Physical affection } \\
\hline$\underline{\mathrm{M}}$ & .0 & .0 & .0 & .01 \\
\hline$\underline{\mathrm{SD}}$ & .0 & .03 & .0 & .06 \\
\hline$\underline{S E}$ & .0 & .0 & .0 & .01 \\
\hline \multicolumn{5}{|c|}{ Positive physical control } \\
\hline$\underline{\mathrm{M}}$ & .0 & .02 & .01 & .01 \\
\hline SD & .03 & .07 & .04 & .05 \\
\hline$\overline{\mathrm{SE}}$ & .0 & .01 & .01 & .01 \\
\hline \multicolumn{5}{|c|}{ Negative physical control } \\
\hline$\underline{M}$ & .0 & .02 & .03 & .08 \\
\hline$\overline{\mathrm{S} D}$ & .0 & .08 & .09 & .21 \\
\hline$\underline{\mathrm{SE}}$ & .0 & .01 & .01 & .03 \\
\hline
\end{tabular}


Table 3

Means and Standard Deviations of Average Rate-per-minute Scores Obtained by Mother-son and Mother-daughter Dyads on the Maternal Teaching Observation Technique (MTOT): Anglo-American and Chicano Samples

\begin{tabular}{|c|c|c|c|c|}
\hline \multirow[b]{2}{*}{ MTOT variables } & \multicolumn{2}{|c|}{ Ang1o-Americans } & \multicolumn{2}{|c|}{ Chicanos } \\
\hline & $\begin{array}{l}\text { Mother- } \\
\text { son } \\
\text { dyads } \\
(\underline{n}=19)\end{array}$ & $\begin{array}{l}\text { Mother- } \\
\text { daughter } \\
\text { dyads } \\
(\underline{\mathrm{n}}=21)\end{array}$ & $\begin{array}{l}\text { Mother- } \\
\text { son } \\
\text { dyads } \\
(\underline{n}=20)\end{array}$ & $\begin{array}{l}\text { Mother } \\
\text { daught } \\
\text { dyads } \\
\underline{\mathrm{n}}=23\end{array}$ \\
\hline \multicolumn{5}{|l|}{ Inquiry } \\
\hline$\underline{M}$ & 2.33 & 2.02 & 1.31 & 1.56 \\
\hline$\overline{\mathrm{SD}}$ & .95 & 1.14 & 1.24 & 2.06 \\
\hline \multicolumn{5}{|l|}{ Directive } \\
\hline M & 1.57 & 1.48 & 2.22 & 2.41 \\
\hline$\overline{S D}$ & 1.20 & 1.01 & 1.84 & 1.63 \\
\hline \multicolumn{5}{|l|}{ Praise } \\
\hline$\underline{M}$ & 3.14 & 3.18 & 1.92 & 2.13 \\
\hline$\underline{\mathrm{S}} \mathrm{D}$ & 2.16 & 1.58 & 1.89 & 1.89 \\
\hline \multicolumn{5}{|c|}{$\begin{array}{l}\text { Negative verbal feedback } \\
\text { or disapproval }\end{array}$} \\
\hline M & .53 & .64 & .63 & 1.04 \\
\hline$\overline{S D}$ & .50 & .47 & .55 & .82 \\
\hline \multicolumn{5}{|l|}{ Modeling } \\
\hline M & .62 & 1.28 & 3.31 & 2.92 \\
\hline$\overline{\mathrm{SD}}$ & 1.00 & 1.49 & 3.23 & 2.69 \\
\hline \multicolumn{5}{|l|}{ Visual cue } \\
\hline M & 2.34 & 2.29 & 2.97 & 3.15 \\
\hline$\underline{\mathrm{SD}}$ & 1.30 & 1.11 & 1.37 & 1.38 \\
\hline \multicolumn{5}{|c|}{ Physical affection } \\
\hline$\underline{M}$ & .0 & .0 & .0 & .01 \\
\hline SD & .0 & .02 & .0 & .04 \\
\hline \multicolumn{5}{|c|}{ Positive physical control } \\
\hline$\underline{M}$ & .0 & .02 & .01 & .01 \\
\hline$\underline{S D}$ & .0 & .06 & .03 & .04 \\
\hline \multicolumn{5}{|c|}{ Negative physical control } \\
\hline$\underline{\mathrm{M}}$ & .0 & .02 & .04 & .07 \\
\hline SD & .02 & .05 & .10 & .14 \\
\hline
\end{tabular}

Any comparisons, using the present data, between Anglo-American and Chicano mothers should take into account the socioeconomic status difference between the two ethnic samples. Recent research indicates that among
Chicanos there is a relationship between certain socioeconomic status variables and maternal teaching strategies (Laosa, 1977, 1978, in press$a$, in press-b). 


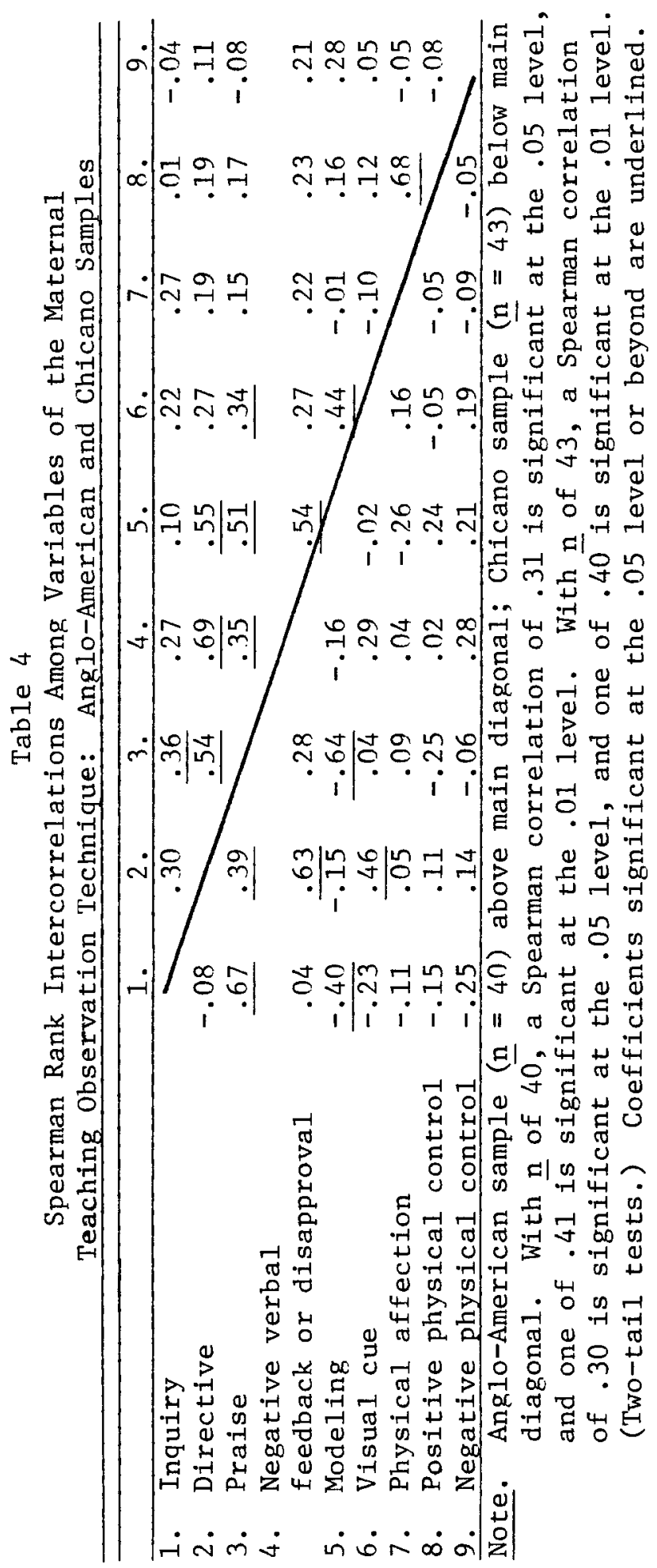




\section{Intercorrelations}

Spearman rank-order correlations, corrected for ties, were computed among the variables of the maternal teaching observation technique, separately by ethnic group. Table 4 presents these coefficients, which are based on summedrate scores. As can be seen, the intercorrelations seem to differ by ethnic group, suggesting that mother-child interactions might be organized differently in these two populations and that construct invariance might not exist across different populations for these measures.

\section{Summary and Discussion}

The purposes of this study were (1) to develop a set of measurement procedures that might reasonably be used in research and evaluation studies of teaching in families; (2) to assess the suitability of these measures for use as variables from the standpoint of psychometric properties; and (3) to determine the adequacy of the measures for use with subjects from two different cultural-linguistic populations, Anglo-Americans and Chicanos. The needed evidence was composed of interobserver reliability, parallel-form consistency, intercorrelations, and comparability of administration procedures across different languages.

The procedures and tasks were sufficiently engaging and appealing, in terms of difficulty level and ability to elicit and to maintain the subjects' attention, for mothers and their 5year-old children. This was true for both AngloAmerican and Chicano subjects. Prior exposure to the tasks did not have any discernible effect on the results. Interobserver reliabilities and parallel-form consistency were adequate, indicating that each MTOT scale measures at least a moderately stable attribute of maternal behavior.

Special measurement issues may arise when an instrument is administered to samples of subjects from several populations. It cannot be assumed that a given instrument measures the same construct in different cultural, linguistic, or socioeconomic groups-or that construct invariance exists across different populations. The apparent differences in intercorrelations obtained in this study suggest that construct invariance might not exist for these measures of maternal teaching strategies across different cultural, language, or socioeconomic populations.

Further investigation seems warranted. Of particular value would be studies of differences in the "meaning" of maternal behaviors in different sociocultural groups. The idea of studying the construct invariance of measurement procedures for different populations is attractive and appears to be essential to the field of measurement. Additional studies should focus on the relationship of personality and demographic characteristics to teaching strategies, the effects that particular parental teaching strategies might have on children's development (see, e.g., Laosa, 1978, 1979a, 1980, in press-b), and whether parental teaching strategies change in relation to experimental manipulations or other educational intervention programs. Other research efforts should be directed at the question of reciprocity, that is, whether parental and offspring behavior follow a process of mutual adaptation (see Laosa, 1979b). Still other studies should examine the development of parent-child interaction as a function of chronological age and family size. Answers to such questions will not only provide evidence useful to the field of measurement but also contribute to an understanding of teaching and learning in the context of the family.

\section{References}

Bandura, A. Social learning theory. Englewood Cliffs, NJ: Prentice Hall, 1977.

Berliner, D. C., \& Gage, N. L. The psychology of teaching methods. In N. L. Gage (Ed.), The psychology of teaching methods. (Seventy-Fifth Yearbook of the National Society for the Study of Education, Part I.) Chicago: University of Chicago Press, 1976. 
Brophy, J. E. Mothers as teachers of their own preschool children: The influence of socioeconomic status and task structure on teaching specificity. Child Development, 1970, 41, 79-94.

Flavell, J. H. Cognitive development. Englewood Cliffs, NJ: Prentice Hall, 1977.

Gagné, R. M. The learning basis of teaching methods. In N. L. Gage (Ed.), The psychology of teaching methods. (Seventy-Fifth Yearbook of the National Society for the Study of Education, Part I.) Chicago: University of Chicago Press, 1976.

Laosa, L. M. Socialization, education, and continuity: The importance of the sociocultural context. Young Children, 1977, 32, 21-27.

Laosa, L. M. Maternal teaching strategies in Chicano families of varied educational and socioeconomic levels. Child Development, 1978, 49, 1129-1135.

Laosa, L. M. The family as facilitator of children's educational development at three years of age: $A$ causal analysis. Paper presented at the Conference on the Family as a Learning Environment, Educational Testing Service, Princeton, NJ, November 1979. (a)

Laosa, L. M. Social competence in childhood: Toward a developmental, socioculturally relativistic paradigm. In M. W. Kent \& J. E. Rolf (Eds.), Primary prevention of psychopathology, Vol. 3: Social competence in children. Hanover, NH: University Press of New England, 1979. (b)

Laosa, L. M. Maternal teaching strategies and cognitive styles in Chicano families. Journal of Educational Psychology, 1980, 72, 45-54.

Laosa, L. M. Maternal behavior: Sociocultural diversity in modes of family interaction. In R. W. Henderson (Ed.), Parent-child interaction: Theory, research, and prospect. New York: Academic Press, in press. (a)

Laosa, L. M. Maternal teaching strategies in Chicano and Anglo-American families: The influence of culture and education on maternal behavior. Child Development, in press. (b)
Moustakas, C. E., Sigel, l. E., \& Schalock, H. D. An objective method for the measurement and analysis of child-adult interaction. Child Development, 1956, 27, 109-134.

Questor Education Products Company. Tinkertoy instruction and idea book. Bronx, NY: Author, 1972.

Sackett, G. P. (Ed.), Observing behavior. Vol. 2: Data collection and analysis methods. Baltimore, MD: University Park Press, 1978.

Sigel, I. E., \& Saunders, R. An inquiry into inquiry: Question asking as an instructional model. In $\mathbf{L}$. Katz (Ed.), Current topics in early childhood education (Vol. 2). Norwood, NJ: Ablex, 1979.

Stallings, J. A., \& Porter, A. National day care home study: Observation component. Final report. Menlo Park, CA: SRI International, in preparation.

\section{Acknowledgments}

This research was supported in part by two grants to the author, a Spencer Foundation faculty research grant through the UCLA Graduate School of Education and Grant RR05729-03 from the Biomedical Research Support Grant Program, Division of Research Resources, National Institutes of Health, through Educational Testing Service. Appreciation is expressed to Dorothy Torres, Perla Pflaster, Luiza Amodeo, Luis Moll, Roberto Rueda, Denise Minden, Tina Rueda, and Patricia Conry-Oseguera for research assistance, and to Jack Krakower and Janet Allen for assistance in data processing.

\section{Author's Address}

Luis M. Laosa, Senior Research Scientist, Educational Testing Service, Princeton, NJ 08541. 